F. Child Lang. 4I (2014), 5 I-83. (C) Cambridge University Press $20 \mathrm{I} 2$.

The online version of this article is published within an Open Access environment subject to the conditions of the Creative Commons Attribution-NonCommercial-ShareAlike licence $<$ http://creativecommons.org/licenses/by-nc-sa/3.0/ $>$. The written permission of Cambridge University Press must be obtained for commercial re-use.

doi:10.1017/So305000912000517

\title{
Annoying Danish relatives: Comprehension and production of relative clauses by Danish children with and without SLI*
}

\author{
KRISTINE JENSEN DE LÓPEZ, LONE SUNDAHL OLSEN \\ Aalborg University, Denmark
}

AND

VASILIKI CHONDROGIANNI

Bangor University, $U K$

(Received I7 December 2010-Revised 3 October 201 I - Accepted 7 September 2012First published online 3 December 2012)

ABSTRACT

This study examines the comprehension and production of subject and object relative clauses (SRCs, ORCs) by children with Specific Language Impairment (SLI) and their typically developing (TD) peers. The purpose is to investigate whether relative clauses are problematic for Danish children with SLI and to compare errors with those produced by TD children. Eighteen children with SLI, eighteen TD age-matched (AM) and nine TD language-matched (LM) Danishspeaking children participated in a comprehension and in a production task. All children performed better on the comprehension compared with the production task, as well as on SRCs compared to ORCs and produced various avoidance strategies. In the ORC context, children with SLI produced more reversal errors than the AM children, who

[*] This study was supported by a grant from The Danish Agency for Science and Technology and Innovation (FKK) to Kristine Jensen de López in support of the NASUD project Normal og Atypisk Sproglig Udvikling (Typical and Atypical Language Development) grant \# 09-063957. We would like to acknowledge the contribution of Line Engel Clasen and Line Boe for assisting in parts of the data collection from the typically developing children. We would like to thank the researchers participating in the COST Action $\mathrm{A}_{33}$ for their discussions related to the production task and to two anonymous reviewers for providing us with helpful comments, which led to the significant improvement of this article. Address for correspondence: Kristine Jensen de López, Clinic of Developmental Communication Disorders, Aalborg University, Department of Communication and Psychology, Kroeghstraede 3, 9220-Aalborg, DK. tel: +45 2782224; e-mail: Kristine@hum.aau.dk 
opted for passive ORCs. These results are discussed within current theories of SLI and indicate a deficiency with the assignment of thematic roles rather than with the structural make-up of RCs.

\section{INTRODUCTION}

Children with Specific Language Impairment (SLI) have been shown to have problems with the acquisition of complex structures which require the structural embedding and displacement of a sentential element from its original position, as in the case of passive sentences (Marshall, Marinis \& van der Lely, 2007; van der Lely, I996), wh-questions (Marinis \& van der Lely, 2007; van der Lely \& Battell, 2003), and relative clauses (RCs) (Friedmann \& Novogrodsky, 2004; Novogrodsky \& Friedmann, 2006). Relative clauses, in particular, have been reported to be severely challenging for children with SLI in both comprehension and production. The underlying causes of these problems have been attributed either to the inability of children with SLI to produce a fully-fledged clause structure (Håkansson \& Hansson, 2000), or to a deficit in movement operations (van der Lely, I 996) and thematic role assignment (Friedmann \& Novogrodsky, 2004; Novogrodsky \& Friedmann, 2006).

To address these theories, most studies have examined the production or comprehension of RCs independently and in different groups of children, with very few studies examining comprehension and production in the same sample of SLI children (Contemori \& Garraffa, 20ıо; Håkansson \& Hansson, 2000). Therefore, the direct comparability of the findings from the two modalities is not always possible. The comparison between the comprehension and production of the same structure in the same group of children is important, as it could help us disentangle the nature of the underlying grammatical problems that children with SLI face.

Furthermore, the experimental studies that explore the comprehension or production of subject and object RCs do not always focus on the avoidance strategies that children with SLI employ when not comprehending or producing the target structure, with very few exceptions (Contemori \& Garraffa, 2010; Håkansson \& Hansson, 2000; Novogrodsky \& Friedmann, 2006; Stavrakaki, 200I). Additionally, existing studies that examine avoidance strategies have been primarily carried out with preschool children whose verbal abilities are low and whose production of complex structures such as relative clauses is limited (Contemori \& Garraffa, 20 10; Håkansson \& Hansson, 2000). Therefore, apart from the production study by Novogrodsky and Friedmann (2006) with school-aged children with SLI, existing production studies examining the acquisition of RCs by children with SLI do not allow us to fully address theories that capitalize on movement or thematic role deficits. 
The present article seeks to address this gap by examining the production and comprehension of relative clauses in the same population of Danishspeaking children with and without SLI. This comparison will shed light on possible production-comprehension asymmetries in both typical and in atypical children in an underexplored Scandinavian (North Germanic) language, namely Danish. As Newmeyer (1997) has stressed, in order to understand the limitations of children with SLI it is crucial to start with a good characterization of the grammatical errors they commit, as these provide an important window into their underlying deficit. The present study seeks to explore the strategies that both TD and SLI children employ when they do not produce the target form. The examination of these strategies will highlight the underlying factors that give rise to the difficulties that impaired children have with complex structures, in comparison to their TD peers.

\section{Relative clauses in Danish}

Relative clauses are complex sentences that involve structural embedding through the use of complementizers such as that or wh-words such as who and which, as well as movement of a noun phrase from within the embedded phrase. RCs are derived by movement of a noun phrase from the subject or the object position to the head of the $\mathrm{RC}$ and co-indexation of the $\mathrm{RC}$ head with its trace within the relative clause (Chomsky, I993; Friedmann \& Novogrodsky, 2004; Guasti, 2002). In a subject relative clause (SRC) as in ( $\mathrm{I}$ ), the noun the girl has moved from the subject position in the embedded sentence to the head of the relative clause, and is co-indexed with its trace within the RC. In an object relative clause (ORC), as in (2), the noun the girl has moved from the object position in the relative clause to being the head of the RC and is co-indexed with its trace within the RC. The thematic role of the moved constituent as an agent, in the case of SRCs, or as a theme, in the case of ORCs, is assigned at the trace position. In order to correctly interpret the sentence, the relationship between the trace and the moved constituent needs to be retained.

( I) Subject relative clause:

I see the girl $\mathrm{i}_{\mathrm{i}}$ that $\mathrm{t}_{\mathrm{i}}$ is kissing the mother

(2) Object relative clause:

I see the $\operatorname{girl}_{\mathrm{i}}$ that the mother is kissing $\mathrm{t}_{\mathrm{i}}$

In Danish, RCs are formed by embedding through the use of two different complementizers, som and der. SRCs employ one of the two complementizers, as in (3), and their presence is obligatory. ORCs, on the other hand, exclusively employ the complementizer som, as in example (4), which can be optional in colloquial speech. 
(3) Subject relative clause:

Feg vil helst vare pigen som/der kysser mor

I would rather be the girl that kisses mommy

'I would rather be the girl that kisses mommy.'

(4) Object relative clause:

$\begin{array}{llllll}\text { feg vil } & \text { helst } & \text { vare } & \text { pigen } & \text { (som) mor } & \text { kysser } \\ \mathrm{I} & \text { would } & \text { rather be } & \text { the girl } \mathrm{i}_{\mathrm{i}} & \text { (that) mommy } & \text { kisses } \mathrm{t}_{\mathrm{i}}\end{array}$

Som and der can also occur together, as in (5), a pattern that is especially frequent in colloquial speech (Vikner, I 99i).

(5) Vi kinder de piger som der vil spise denne kage

We know the girls that will eat this cake.

'We know the girls (of the sort) that will eat this cake.'

When used in isolation, som has been argued to occupy the head of the complementizer phrase, which is $\mathrm{C}^{0}$ (Vikner, I99I). The status of the complementizer der is more controversial. Vikner (I99I) argues that it is a true complementizer, like som, and it therefore occupies the head of the complementizer phrase $\left(\mathrm{C}^{0}\right)$. Taraldsen ( $\left.199 \mathrm{I}\right)$, on the other hand, proposes that $d e r$ is an expletive subject and as such it occupies the SpecIP. In the present article, we will assume that both complementizers occupy the head of the complementizer phrase, at least when used in isolation. What this means from an acquisition perspective is that, when children produce a relative clause with som or with der or with both, they are able to project a fully-fledged clause structure up to the CP level.

\section{Relative clauses in typical and atypical acquisition}

The acquisition of subject and object relative clauses has been extensively studied in TD children acquiring various languages (de Villiers, Tager-Flusberg, Hakuta \& Cohen, I979; Diessel \& Tomasello, 2000; Eisenberg, 2002; Hamburger \& Crain, 1982, for English; Friedmann, Belletti \& Rizzi, 2009, for Hebrew; Kidd, Brandt, Lieven \& Tomasello, 2007, for German; Adani, 201 I; Crain, McKee \& Emiliani, ı990, for Italian). Studies have shown that relative clauses emerge as early as the age of three years (McKee \& McDaniel, 200I; Diessel \& Tomasello, 2000), although acquisition depends on the language being acquired, the modality being investigated-i.e. comprehension vs. production - and the relative clause type. For example, early comprehension studies have shown that children do not exhibit adult-like knowledge of restrictive $\mathrm{RCs}$, such as "The cow that kicked the elephant is big" until the age of five (Kidd \& Bavin, 2002), yet they are able to produce restrictive RCs in presentational contexts, such as "Here's the tiger that's gonna scare him" at the age of $2 ; 2$ 
(Diessel \& Tomasello, 2000). However, early acquisition studies have been criticized for methodological shortcomings and for not creating felicitous conditions for target-like RC comprehension (Adani, 20 I I ; Hamburger \& Crain, I 982). One study, by Hamburger and Crain (1982), showed that TD English-speaking children were able to comprehend and produce restrictive RCs above chance at the age of four years when felicitous discourse-related conditions were created for the interpretation and production of RCs, suggesting that RCs are acquired from early on (Guasti, 2002).

With regards to Danish, to date there is only one study investigating the comprehension and production of RCs in TD Danish-speaking children. In a cross-sectional study, Jensen de López and Sundahl Olsen (2010) examined the comprehension of SRCs and ORCs in I 32 five- to eleven-year-old TD Danish-speaking children using an adapted version of the picture selection comprehension task developed by Friedmann and Novogrodsky (2004). Jensen de López and Sundahl Olsen (2010) found that comprehension of SRCs was at ceiling as early as the age of five. Comprehension of ORCs, on the other hand, exhibited a gradual development, with five-year-olds showing accuracy of $66 \%$, the nineyear-olds showing an increase in accuracy to $76 \%$, and eleven-year-olds reaching ceiling accuracy at 9i \%. Jensen de López and Sundahl Olsen (2010) also investigated the production of SRCs and ORCs by twenty TD Danish five-year-old children using the adapted version of Novogrodsky and Friedmann's (2006) preference task. According to their findings, SRCs were produced more accurately than ORCs. Additionally, children primarily produced SRCs containing a passive, such as Drengen som bliver fotograferet af faren 'The boy that is photographed by the father', when prompted to produce an ORC, such as Drengen som faren fotograferer 'The boy that the father photographs'. In this article we will call this particular avoidance strategy a 'passive object relative' or 'passive ORC', following Belletti (2009). It should be noted that passives have been shown to be accurately comprehended by TD Danish-speaking children by the age of five, and earlier than in children acquiring other languages, such as Hebrew or Catalan. This was shown in a large-scale cross-linguistic study of eleven languages using the same methodology (Armon-Lotem et al., unpublished observations).

Turning to children with SLI, the comprehension and production of relative clauses has been shown to be particularly difficult for these children across typologically different languages, e.g. English (Schuele \& Dykes, 2005 ; Schuele \& Nichols, 2000; Schuele \& Tolberrt, 200 I ; van der Lely \& Battell, 2003), Swedish (Håkansson \& Hansson, 2000), Hebrew (Friedmann \& Novogrodsky, 2004; Novogrodsky \& Friedmann, 2006), Italian (Contemori \& Garraffa, 2010), and Greek (Stavrakaki, 200ı ; 2002). The few studies that have investigated comprehension and production in the 
same group of children report that comprehension exhibits higher accuracy than production (Contemori \& Garraffa, 2010; Håkansson \& Hansson, 2000). At the same time, it has been shown that SRCs are easier to comprehend or produce compared to ORCs (Friedmann \& Novogrodsky, 2004). However, the particular studies differ in terms of the age of the children with SLI being investigated (preschool or school-aged children). Furthermore the specific errors that children commit seem to be dependent upon the children's age (Novogrodsky \& Friedmann, 2006), as well as the particular language being acquired.

Håkansson and Hansson (2000) examined the production and comprehension of SRCs in a longitudinal study of ten Swedish preschool children with SLI (mean age: 5;0) and ten younger language-matched (hereforth LM) TD children (mean age: 3 ; 5). All children were tested on a battery of comprehension tasks (picture-pointing, act-out task, and an oral response) and production (sentence completion, elicited imitation) administered twice within a six-month period. Children with SLI performed equally well as the TD children on all tasks tapping comprehension, although there were large individual differences within and between groups. The groups differed in their accuracy in the production tasks. Whereas the TD Swedish children produced fully-fledged relative clauses from the age of three years (cf. Lundin, i987), the children with SLI had significantly more incorrect responses than their TD peers, and still differed from them at Time 2 (six months later). Håkansson and Hansson (2000) also investigated the relationship between comprehension and production, and found that TD children exhibited no asymmetry at Time I; however, an asymmetry surfaced at Time 2 showing better performance on production compared to comprehension. The children with SLI, on the other hand, exhibited better performance on comprehension compared to production at Time I, while there was no significant modality difference at Time 2, even though their performance on both modalities increased. Most of the incorrect responses in the production were omissions of the complementizer som; these omissions occurred significantly more often in the SLI children than in the TD children. As mentioned, there was a development from Time I to Time 2 for both groups of children, with children with SLI producing significantly fewer complementizer omissions at Time 2 (from $77 \%$ to $37 \%$ ).

The same asymmetry in comprehension and production, as well as differences in error patterns, have been reported for Italian preschool children with SLI. In a small-scale study, Contemori and Garraffa (2010) compared the comprehension and production of relative clauses by four Italian preschool children with SLI with two groups of TD children; an age-matched (AM) group and a seven- to eleven-months-younger group. The comprehension task was a replication of Friedmann and 
Novogrodsky's (2004) picture selection task. Contemori and Garraffa (2010) reported that children with SLI performed equally well on the comprehension of SRCs and ORCs as the AM children, and better than their younger peers on the comprehension of SRCs. In terms of production, the children with SLI had significantly lower accuracy than the AM and their younger peers on both SRCs and ORCs. In terms of errors, the language-impaired children omitted the complementizer more frequently compared with the two groups of TD children who never committed such errors. Additionally, the younger TD and the children with SLI exhibited better performance on the comprehension compared with the production of ORCs; for the AM group there was no discrepancy between the two modalities on either SRCs or ORCs.

Complementizer omission by preschool children has also been found in studies with English-speaking children with SLI. Schuele and Dykes (2005) and Schuele and Tolberrt (200I) analyzed relative clauses in spontaneous production data from a longitudinal case study with one English-speaking language-impaired child. The child's initial production of relative clauses was at the age of $4 ; 8$ years and mainly consisted of subject relative clauses with omitted relative markers (that or wh-pronouns). The very few object relatives that were produced also included omissions of obligatory relative markers.

Studies with older children with SLI have shown that problems with projecting a fully-fledged structure and with producing complementizers are less prominent. Friedmann and Novogrodsky (2004) investigated the comprehension of simple SVO sentences, SRCs, and ORCs in nine-year-old Hebrew-speaking children with SLI in comparison with two younger groups of TD children (six-year-olds and four-year-olds). They employed a picture selection task and found that the TD six-year-old children were above chance in the comprehension of all structures. Children with SLI, on the other hand, and the four-year-old TD children, had higher accuracy on the simple SVO sentences and the SRCs, but were at chance level on the ORCs.

In another study with older Hebrew-speaking children with SLI (mean age: I $2 ; 6)$, Novogrodsky and Friedmann (2006) examined the production of SRCs and ORCs using a preference task and a picture description task. They report that children with SLI were significantly poorer on producing SRCs and ORCs in both tasks compared to the TD controls. At the same time they were more accurate on SRCs compared to ORCs, confirming the asymmetry between subject and object relatives found in comprehension. The study also investigated the strategies employed by the children when they avoided producing SRCs and ORCs. They found that avoidance strategies for SRCs primarily consisted of simple declarative clauses, and avoidance strategies for ORCs consisted of theme 
or role reversals and simple SVO sentences. Passive object relatives were very infrequent, and, according to Novogrodsky and Friedmann (2006), passives are very infrequent in Hebrew. Importantly, the passives that children produced in an RC context were claimed not to constitute true verbal passives, but rather to be adjectival passives. This type of passive has also been reported to be unproblematic for English-speaking children with SLI, and since adjectival passives do not require any movement it has been concluded that children with SLI have problems with A-movement, and therefore adjectival passives are easier than true actional passives (van der Lely, I996). Hebrew-speaking children with SLI did not make any complementizer omissions, suggesting that school-aged children with SLI do not have problems projecting a fully-fledged clause structure. Lack of complementizer omissions in older children with SLI was also found in a study by Stavrakaki (2002) with older Greek-speaking children with SLI (mean age: 7;4). The Greek children with SLI, similarly to the Hebrew children, produced more role reversals than the TD children.

\section{Theories of SLI and the acquisition of relative clauses}

Various theories have been proposed to account for the difficulties that preschool and school-aged children with SLI exhibit with RCs. These cluster in four groups according to the source of the difficulty: (a) a structural deficit related to projecting a fully-fledged clause structure (Håkansson \& Hansson, 2000; Meisel \& Müller, I992); (b) linearly-driven parsing (Cromer, I978); (c) impaired thematic role assignment (Friedmann \& Novogrodsky, 2004; Novogrodsky \& Friedmann, 2006); and (d) deficits in the movement operations ( $\mathrm{A}^{\prime}$-movement) within the computational system (van der Lely, I996; van der Lely \& Battell, 2003).

According to theories that evoke the importance of structural deficiencies (Håkansson \& Hansson, 2000; Leonard, I998), children with SLI have difficulties with functional categories, including complementizers, and thus have problems projecting a fully-fledged clause structure. Following Meisel and Müller (I992), the difficulty with acquiring complementizers arises from the fact that they developed out of prepositions. Young children first comprehend complementizers as prepositions; they later need to reorganize this notion and realize that complementizers are used to mark hierarchical relationships. In this respect, this account predicts that the inability to parse a fully-fledged clause structure will lead to chance or below chance performance in comprehension, although this is task dependent and it decreases with age (Håkansson and Hansson, 2000). As for production, children who have problems marking hierarchical relationships by subordination may employ avoidance strategies such as coordination, 
non-conjunctional clauses, or dummy place holders (Håkansson \& Hansson, 2000). As for the relationship between comprehension and production, children with SLI are expected to perform better on comprehension compared with production.

Following theories capitalizing on linear order (Cromer, I978), children with SLI do not possess the syntax required for the assignment of thematic roles, and their interpretation is based solely on the linear order of the sentential constituents. A linear assignment of roles in SRCs will lead to the correct interpretation because the first noun phrase happens to be the agent and the second is the theme. In ORCs, however, such a strategy will lead to a reversed interpretation of the sentence. Thus, children with SLI are predicted to perform well on SRCs, but consistently badly on ORCs. These predictions are articulated with respect to comprehension, but it is unclear what the predictions would be in terms of production.

According to the Representational Deficit for Dependent Relationship theory (RDDR; van der Lely, I996), the deficit is understood as due to the SLI children's syntactic computational system. Specifically, the deficit is related to SLI children's impairment with $\mathrm{A}^{\prime}$-movement, which makes them treat movement as optional, rather than obligatory. Such an approach claims that, in the cases in which the children with SLI do not represent this movement, the assignment of thematic roles to noun phrases that have undergone long-distance movement will be optional and this will be exhibited as chance performance. These predictions have been made for both the comprehension and production of wh-questions in studies by van der Lely, (1996) and van der Lely and Battell (2003), but not for relative clauses.

Friedmann and Novogrodsky (2004), following Grodzinsky (I990), argue that SLI children's poor comprehension and production of RCs lies in their inability to assign thematic roles to noun phrases that have moved from their original sentence position. If a moved constituent cannot be assigned a thematic role at its trace position, then a non-syntactic strategy adopted by children with SLI would be to assign a thematic role according to its position within the sentence. This means that the first noun phrase within the sentence could be assigned the 'agent' role regardless of whether the noun phrase carries the role of the agent or of the theme. In terms of comprehension, then, this account predicts that performance on SRCs is better than performance on ORCs, since in SRCs, the first noun that is encountered when the sentence is parsed carries the role of the agent. In ORCs, however, where the noun has been displaced from its original position as the patient/theme, the first noun that occurs when parsing the sentence is not the agent. When a child is faced with the mismatch between position in the sentence and thematic role assignment, s/he may rely on a guessing strategy in order to assign a thematic role. This leads to 
chance-level performance on the comprehension of ORCs. Regarding production, Novogrodsky and Friedmann (2006) predict that a deficit in movement and thematic role assignment will manifest itself as errors related to thematic roles. However, what this account does not explain is why the children with SLI in their study opt for the strategy of producing SRCs, with role reversal errors, instead of the target ORC. Therefore, it does not explain why movement from subject position is easier than movement from object position.

An explanation for this finding has recently been put forward by Friedmann et al. (2009) in terms of intervention effects. The account has been proposed for TD children. However, we argue that it can be extended to the acquisition of RCs by children with SLI in order to capture both the asymmetry between SRCs and ORCs, and also the types of errors that children with SLI and their TD peers commit when not producing a target ORC. ${ }^{1}$

More specifically, Friedmann et al. address the asymmetry between SRCs and ORCs by appealing to (a) the different extraction sites out of which movement occurs in SRCs and ORCs, and (b) the fact that in the case of ORCs there is an intervening noun, the subject of the relative clause, which renders movement more difficult for TD children. The noun intervenes between the head of the relative clause and the position within the relative clause out of which it has moved and with which it establishes an A'-dependency. This account capitalizes upon Rizzi's (r990) Relativised Minimality (RM) effect, according to which a local relation cannot hold between $\mathrm{X}$ and $\mathrm{Y}$ when $\mathrm{Z}$ intervenes and it is a potential candidate for the local relation, as in (6):

(6) X... Z... Y

In this configuration, $\mathrm{X}$ is the 'target' of the local relation that is the landing site of movement, $\mathrm{Z}$ the 'intervener' and Y the 'origin'. In the ORC example the girl that the grandmother is kissing, the lexical NP the girl is the target, the grandmother the intervener, and kissing the origin. However, in the SRC example the girl that is kissing the grandmother, there is no intervening noun between the origin, which is the subject position of kissing and the target the girl. According to Friedmann et al. (2009), typically developing children are sensitive to the intervention effects that are created in ORCs when the target (the girl) and the intervener (the grandmother) share a structural similarity; in this case they are both full lexical NPs.

This account makes the following two predictions. The first prediction is that TD children will perform better on SRCs compared to ORCs in both

[I] Sensitivity to intervention effects in the case of adults with acquired language impairment (agrammatism) have been addressed in Grillo (2008). 
comprehension and production, due to the absence of intervention effects in the case of SRCs. The second prediction relates to production and suggests that TD children will not only have more target responses for SRCs, but that they will also produce more SRCs in place of ORCs to compensate for the intervention effects found in ORCs. These SRCs will consist primarily of passive object relatives, as in the girl that is kissed by the grandmother (passive ORC) instead of the girl that the grandmother is kissing (active ORC). Such intervention effects and avoidance strategies have been shown in a recent study by Belletti and Contemori (2010) with TD Italian children, who opted for SRCs with passives instead of ORCs.

Extending this account to language impaired children, we would predict that children with SLI will also be sensitive to the same intervention effects as their TD peers, exhibiting similar patterns; that is better performance on SRCs compared to ORCs in both comprehension and production. At the same time, and given that children with SLI have been shown to have problems with A- and A'-movement (van der Lely \& Battell, 2003) and with thematic role assignment (Friedmann \& Novogrodsky, 2004; Novogrodsky $\&$ Friedmann, 2006), we would expect them to adopt different avoidance strategies compared with their TD peers, opting for fewer passive object relatives, as these also require movement. We propose that Friedmann et al.'s (2009) account of TD children's sensitivity to intervention effects could be extended to children with SLI, not only to capture their sensitivity to intervention effects, but also in order to explain the avoidance strategies adopted by these children in the case of ORCs.

\section{Present study}

To date there are no other studies investigating the comprehension or production of subject and object relative clauses in Danish children with SLI. Our study is the first experimental study that consistently compares comprehension and production in the same samples of TD and SLI children employing similar methodologies used in previous studies with children with SLI (Friedmann \& Novogrodsky, 2004; Novogrodsky \& Friedmann, 2006). This continuity in the methodology allows a high degree of comparability with previous studies and permits us to ascertain whether or not the difficulty in acquiring relative clauses reported for other languages is also present in typically and atypically developing Danish children. Danish is an underexplored Scandinavian (North Germanic) language, in which relative clause formation follows a fixed word order, as in English. At the same time, it has certain intricacies, such as the interchangeable use of two different complementizers (som and der) in subject position and the optional use of the complementizer som in object position. This makes it a fruitful testing ground for theories capitalizing on structural deficits (Håkansson \& 
Hansson, 2000) by exploring the type of complementizers produced in SRCs and ORCs by the TD and the language impaired children. At the same time, we can address theories arguing for deficits in movement or thematic role assignment by exploring the types of errors that SLI children commit when not producing the target structure. Finally, the present study will follow Friedmann et al.'s (2009) account in addressing intervention effects in TD Danish children, as has been argued for TD Italian and Hebrew children, and therefore it will, for the first time, further explore whether or not children with SLI are also sensitive to these effects.

In the present study we examined the comprehension and production of SRCs and ORCs in children with SLI and their age-matched and language-matched typically developing peers. The specific research questions that we asked were whether or not: (a) Danish children with SLI differ from AM and LM Danish children in their comprehension of SRCs and ORCs; (b) Danish children with SLI differ from AM and LM Danish children in their production of SRCs and ORCs; (c) Danish children with SLI follow similar avoidance strategies as AM and LM Danish children, when they do not produce the target subject or object relative clause; (d) Danish children with SLI differ from AM and LM children in the number and type of complementizers that they produce; and finally (e) the relationship between production and comprehension is the same for the three groups.

Despite production-comprehension asymmetries in child language still not being fully understood, based on the studies and accounts introduced in the previous sections, we predict that both the TD and the SLI groups will perform better on comprehension compared to production. Extending this rationale to children with SLI, we would expect their performance on comprehension to be better compared to their performance on production. Furthermore, given that the various accounts of SLI postulate deficits in particular areas of the linguistic system, we would also expect these deficits to emerge in both modalities, yet to a different degree. These deficits would manifest themselves both as lower accuracy on the target structure, and as different strategies employed to avoid using the target RCs.

Additionally, if intervention effects are operative in the case of TD children and children with SLI, then they should show lower accuracy with SRCs compared to ORCs. At the same time, and given that SLI children have problems with long-distance movement, we expect them to perform worse than their TD peers at least on the production and comprehension of ORCs. In terms of avoidance strategies, and given that passive object relatives have been shown to be the predominant strategy in preschool TD Danish children (Jensen de López \& Sundahl Olsen, 2010), we will explore the degree to which this particular strategy is also adopted by the TD and SLI children in our study. 
METHOD

\section{Participants}

Forty-five monolingual Danish-speaking children participated in the present study. Eighteen of the children had been diagnosed with combined expressive and receptive language impairment prior to the study and had been receiving clinical service by a language therapist at the time of testing. The children with SLI were recruited through contact with speech-language therapists. They all met the criteria for SLI as described in Leonard (1998). They had normal hearing, no history or symptoms of significant medical, neurological, physical, or emotional problems, as determined by parent responses to a written questionnaire, and no apparent structural oral-facial defect. Twelve children were boys and six children were girls. They ranged in age from $5 ; 0$ to $8 ; 4$ (mean $6 ; 3$, SD: 12.9 months). All children were tested on the Danish Standardization of the Test for Reception of Grammar (Bishop, 20I0). Children with SLI were all at least $\mathrm{I}_{5} \mathrm{SD}$ below the standardized score for their age on the Danish TROG-2. Children's performance IQ was assessed with two subtest from the Wechsler Preschool Primary Scale of Intelligence - Revised (WPPSI; Wechsler, 2004) for the children aged $\geqslant 7 ; 3$, and with Wechsler Intelligence Scale for Children (WISC; Wechsler, I99I) for the children $\leqslant 7 ; 3$ years. Each child had a non-verbal intelligence score in the normal range $(>85)$.

A group of eighteen children with typical language development served as age-matched controls (hereafter referred to as AM children) to the children with SLI. Their age ranged from $5 ; 0$ to $8 ; 2$ (mean $6 ; 3$, SD: I3.I months). Ten AM children were boys. Each child in this group was within two months of the age of a child in the SLI group. The remaining nine children were younger typically developing children matched with the SLI children on their language abilities as determined by TROG-2 (raw scores)-hereafter referred to as LM children. The mean raw score for the SLI children was $49 \cdot 6$ (SD: 9.4, range: 35-68) and for the LM children their mean raw score was 55.9 (SD: I I.3, range: 36-69). An ANOVA test including post-hoc comparisons with Bonferroni correction showed that the AM children, but not the LM children, differed significantly from the children with SLI in their mean scores on the TROG $(p>0 \cdot \mathrm{I})$. The LM children were between $4 ; 0$ to $6 ; 5$ (mean $6 ; 4$, SD: 7.9 months) and three of them were boys. None of the AM and LM children had a history of speech-language problems or any learning difficulties. They all performed at age-average level academically, according to reports from parents and classroom teachers. None of the children received any special services. 


\section{Experimental tasks}

The experimental tasks consisted of a comprehension task and an elicited production task of subject and object relative clauses. Both tasks were adapted to Danish from their Hebrew versions originally developed by Friedmann and Novogrodsky (2004) and Novogrodsky and Friedmann (2006).

Comprehension of relative clauses. The comprehension task was a binary sentence-picture matching task consisting of twenty different coloured picture pairs (Friedmann \& Novogrodsky, 2004). One picture of the pair matched the sentence, whereas the other picture depicted the reverse action. The task included three sentence types: active sentences with canonical subject-verb-object (SVO) order, subject relative clauses, and object relative clauses. They were twenty items per sentence type, yielding sixty sentences in total. We used the same transitive verbs for all three sentences types ('bite', 'splash', 'draw', 'lick', 'pull', 'touch', 'cover', 'dry', 'kiss', 'photograph', 'hug', 'wash', 'swing', 'brush', ‘feed', 'pinch', 'help', 'carry', 'lift', and 'tickle'). There were twenty nouns depicting animate characters that were the same across sentence types ('cat', 'dog', 'boy', 'father', 'soldier', 'doctor', 'giraffe', 'cow', 'rabbit', 'penguin', 'king', 'dwarf', 'mother', 'girl', 'grandfather', 'monkey’, 'hippo', 'grandmother', 'nurse', and 'monkey'). All sentences were semantically reversible. Examples of the sentence types are given in $(7 \mathrm{a}-\mathrm{c})$.

\section{(7) a. Giraffen slikker koen/koen slikker giraffen (SVO)}

'the giraffe is licking the cow/the cow is licking the giraffe.'

b. Dette er giraffen, der slikker koen (SRC)

'this is the giraffe that is licking the cow.'

c. Dette er giraffen, som koen slikker (ORC)

'this is the giraffe that the cow is licking.'

The children were instructed to listen carefully to the experimenter and to point to the picture that best illustrated what they heard. The children were first tested on a warm-up item presenting an active sentence to assure that they understood the task. Each picture pair was then presented to the child three times; one for each sentence type, and followed a randomized order of presentation.

Production of relative clauses. The production task was a preference elicitation task adapted to Danish from Novogrodsky and Friedmann (2006). The child was presented with two options and was asked to choose which one $\mathrm{s} /$ he preferred. The task was constructed in such a way that the response would have to be formulated as a relative clause. The task consisted of twenty sentences; half of them elicited subject relatives and half object relatives. A total of eleven nouns were used to depict the animate characters ('aunt', 'boy', 'doctor', 'elephant', 'father', 'friend', 
'grandfather', 'grandmother', 'mother', 'neighbour', and 'teacher'), and nine nouns were used to depict the inanimate objects ('coke', 'water', 'present', 'ice-cream', 'chocolate', 'radio', 'shower', 'alarm', and 'ball’). These nouns were the same across sentence types. The target head noun of the relative clause was always the animate participant that had the role of the patient or the agent depending on whether a subject or an object relative was elicited. Sentences were manipulated for reversibility. There were six reversible sentences and four irreversible sentences per condition (SRC and $\mathrm{ORC}$ ). In the reversible condition the participants were always animate, as in (8a), whereas in the irreversible condition there was one animate participant and one inanimate object, as in (8b).

(8a) is an example of the instruction given and of the target response for the elicitation of an object relative (reversible condition):

(8) a. EXPERIMENTER: Der er to piger, bedstemoren kysser en pige, bedstemoren knuser en pige. Hvilken pige vil du helst vare? Du skal starte med at sige: $\mathcal{F e g}$ vil helst vare pigen ...

TARGET RESPONSE: Feg vil helst vare pigen (som) bedstemor kysser. EXPERIMENTER: "There are two girls. The grandmother kisses one girl, the grandmother hugs one girl. Which girl would you rather be? Start with: I would rather be the girl ...'

TARGET RESPONSE: 'I would rather be the girl that grandmother kisses.'

(8b) is an example of the instruction given and of the target response for the elicitation of a subject relative (irreversible condition):

(8) b. EXPERIMENTER: Der er to piger, en pige drikker cola og en pige drikker vand. Hvilken pige vil du helst vare? Du skal starte med at sige: Yeg vil helst vare pigen ...

TARGET RESPONSE: Feg vil helst vare pigen der/som drikker vand. EXPERIMENTER: 'There are two girls. ${ }^{2}$ One girl drinks coke, one girl drinks water. Which girl would you rather be? Start with: I would rather be the girl ...' or 'The girl ...'

TARGET RESPONSE: 'I would rather be the girl that drinks water.'

There were twelve verbs in the irreversible condition ('drink', 'eat', 'examine', 'spray', 'lift', 'wake-up', 'receive', 'give', 'find', 'buy', 'warm-up', and 'cool down') and twelve verbs in the reversible condition ('draw', 'scare', 'met', 'invite', 'visit', 'photograph', 'hug', 'kiss', 'seek', 'find', and 'comb'; 'hug' was repeated twice). The test sentences were controlled for length and were between nine and eleven words per sentence. The presentation order was randomized.

[2] When elicited with boys the protagonist was a boy. 
The children were instructed to help the experimenter investigate what children prefer to do by telling the experimenter their own preferences. They were then presented with a forced-choice task and told always to start their sentence with the magic words $\mathcal{F}$ eg vil helst vere pigen 'I would rather be the girl'. The children participated in a warm-up session to be sure they understood the task and corrected if they failed to start the sentence with the magic words 'I would rather be ...'. All the elicited sentences were audio-recorded and transcribed on-line during the test session and later checked from the recordings. All codings were checked for agreement by two of the authors.

\section{Procedure}

The children were tested in a quiet room in their kindergarten or after-school activity centre in Denmark. The relative clause tasks form part of a larger study on language impairment in Danish-speaking children. Only the tasks relevant for this study are mentioned in this article. Each child was tested individually in five 45-minutes sessions. No child failed to complete the warm-up or the experimental session. All children participated in both tasks.

\section{Data coding and scoring}

In the comprehension task we calculated the proportion of correct responses for each sentence type, i.e. simple SVO sentences, subject relative, and object relative clauses in the corresponding context.

In the production task, the various types of responses that were elicited were coded as follows. Sentences (9) to (I 7 ) indicate the codings for the nine types of responses.

Lead-in sentence: 'I would rather be the girl/boy ...' :

(a) Subject relative clause and response types

(9) pigen som/der kysser bedstemoren (subject relative clause-SRC) 'the girl that kisses the grandmother.'

( 'the girl that kisses the grandmother.'

(I I) *ham kysser bedstemoren (complementizer omission) 'him kisses the grandmother.'

(b) Object relative clause and response types

( 12) pigen (som) bedstemoren kysser (object relative clause-ORC) 'the girl that the grandmother kisses.'

(I3) pigen som bliver kysset af bedstemoren

(SRC with passive - Passive ORC)

'the girl that is kissed.'

(by the grandmother) 
(14) pigen som kysser bedstemoren

(SRC with role reversal)

'the girl that kisses the grandma.'

( 5 ) bedstemoren som kysser pigen

(SRC with head reversal)

'the grandma that kisses the girl.'

(c) Common response patterns for SRCs and ORCs

( 6 ) pigen kysser bedstemoren

'the girl kisses the grandmother.'

(simple SVO)

(I7) kysser (fragment)

'kisses.'

Sentences (9) and (12) are the target responses for subject and object relative clauses respectively. Sentences with a doubled complementizer, as in (Io), were also considered target responses. Sentences (I3) to (I 7) indicate the various avoidance strategies that the children used, when they did not produce a target relative clause. These avoidance strategies constituted non-target responses, which were either grammatical or ungrammatical. Passive sentences and head or role reversals are relativized clauses, but are not-target responses in the object relative context, as the ORC is transformed into an SRC. Of these three avoidance strategies, a passive sentence is the only strategy which preserves the meaning of the ORC. Complementizer omission is an ungrammatical option in SRCs (jeg vil helst vare pigen $\left(*_{\text {som }} /\right.$ der $)$ kysser mor) but not in ORCs (jeg vil helst vare pigen (som) mor kysser). Simple sentences, like (I6), constitute grammatical nontarget options, whereas fragments, like (I7), are ungrammatical non-target options. All null responses indicating the child's inability to produce any answer to the probe were excluded from the count. There were three null responses from the $\mathrm{AM}$ children, one from the LM children, and thirteen from the SLI children, indicating that the number of missing data was small.

Scoring followed different procedures to reflect the various research questions. First, in order to examine whether or not the task was felicitous at eliciting relative clauses regardless of whether or not it was the target relative clause in a specific context, we calculated the number of RCs produced in each context. This calculation included also non-target RCs in a specific RC context, e.g. a subject relative clause with a passive in an object relative clause elicitation context. According to this calculation, responses (I3)-(I 5) were considered felicitous responses for ORC contexts.

Second, we calculated the proportion of target RCs in a specific RC context, e.g. the number of subject relative clauses produced in a subject relative clause elicitation context. This calculation regarded all other response types as errors or avoidance strategies.

Then, we calculated the proportion of each avoidance strategy out of the total avoidance strategies produced in a subject or object relative clause 
context. In the case of the SRC context, the avoidance strategies that were used were complementizer omissions, as in (II), simple SVO sentences where a simple sentence was produced, as in (I6), and fragmented sentences, as in (I7). In the case of the ORCs, the avoidance strategies that were used were (I3)-(I7).

Finally, we calculated the type of complementizers produced in SRCs and in ORCs. As mentioned above, in the SRCs either der or som can be used, and their presence is obligatory. Complementizer omission hence constitutes an ungrammatical option. However, in the calculation we also included complementizer omission, as this may be a possible option in children's grammar regardless of grammaticality. Another structure that the children produced was som der, as in (ro). In the ORC context, the production of the complementizer som is optional, and therefore its omission constitutes a grammatical option.

\section{RESULTS}

\section{Comprehension of relative clauses}

First, we calculated children's accuracy on the comprehension of simple SVO sentences, and subject and object relative clauses (SRC, ORC), as presented in Figure $\mathbf{I}$.

To examine whether or not the AM, the LM, and the children with SLI differed in their comprehension of simple SVO sentences, SRCs, and ORCs, we performed a three-way (Clause Type: SVO, SRC, ORC) $\times$ three-way (Group: AM, LM, SLI) ANOVA. This revealed a main effect of Clause Type $\left(F(2,84)=\mathrm{I} 08.83 \mathrm{I}, p<0.00 \mathrm{I}, \eta^{2}=0.722\right)$, a main effect of Group $\left(F(\mathrm{I}, 42)=23.206, \quad p<0.00 \mathrm{I}, \quad \eta^{2}=0.525\right), \quad$ and a significant interaction between Clause Type and Group $\left(F(2,84)=\right.$ I $\left.7.02 \mathrm{I}, p<0.00 \mathrm{I}, \eta^{2}=0.448\right)$. Three one-way ANOVAs with post-hoc comparisons with Bonferroni correction showed that the three groups did not differ in terms of SVO and SRCs (SVO \& SRC: $p>0 \cdot 2$ ); the three groups differed in their accuracy on ORCs $(F(2,44)=32.960, p<0.00 \mathrm{I})$, as the children with SLI had significantly lower accuracy than both the AM and the LM children on ORCs $(p<0.00 \mathrm{I})$.

To unpack the interaction between clause type and Group we ran two three-way ANOVAs (Clause type: SVO, SRC, ORC) for each group separately. For all groups a significant main effect of Clause Type was found (AM: $F(2,34)=2 \mathrm{I} \cdot 0 \mathrm{I} 0, p<0 \cdot 00 \mathrm{I}, \eta^{2}=0.553 ; \mathrm{LM}: F(2, \mathrm{I} 6)=\mathrm{I} 3 \cdot 486$, $\left.p<0.00 \mathrm{I}, \eta^{2}=0.628\right)$, but for the children with SLI this effect was more pronounced $\left(F(\mathrm{I}, \mathrm{I} 8)=\mathrm{I} 22.50 \mathrm{I}, p<0.00 \mathrm{I}, \eta^{2}=0.878\right)$, as the effect size indicates, suggesting that the children with SLI performed significantly poorly on ORCs. Pairwise comparisons with Bonferroni correction for each group separately also showed that there was no difference between SVO and 


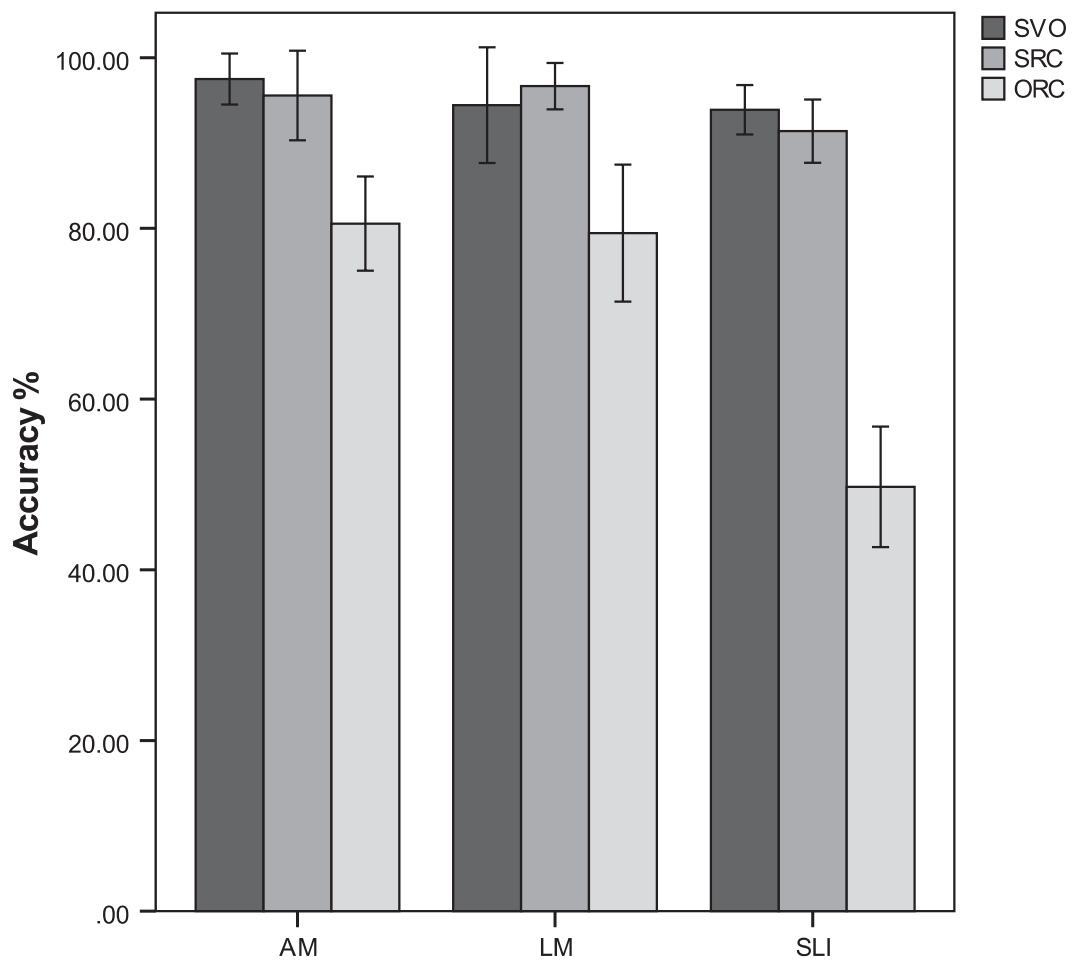

Fig. I. Percentage of accurate responses in the comprehension task by the age-matched children (AM), the language-matched children (LM), and the children with SLI.

SRCs for any of the groups $(p>0 \cdot I)$. The main difference was between ORCs and the other two clause types for all groups (AM: SVO vs. SRC: $p=0.00 \mathrm{I}$; SVO vs. ORC: $p<0.00 \mathrm{I}$; LM: SVO vs. SRC: $p=0.0 \mathrm{I}$; SVO vs. ORC: $p<0.05$; SLI : SVO vs. SRC: $p<0.00 \mathrm{I}$; SVO vs. ORC: $p<0.00 \mathrm{I})$.

We further examined whether children's performance differed from chance. In the SVO sentences all children performed above chance (AM, LM, SLI : $p>0.05$ ). In the SRCs, all children from all groups performed above chance, apart from one child from the AM group who performed at chance level (55\%). The LM and AM TD children performed above chance in the ORCs. However, the SLI children's performance on ORCs did not differ from chance $(t(\mathrm{I}, \mathrm{I} 7)=2 \cdot 778, p>0 \cdot \mathrm{I})$.

\section{Production of relative clauses}

First, we examined whether the task was felicitous at eliciting relative clauses. To do this, we calculated the number of RCs produced in the 


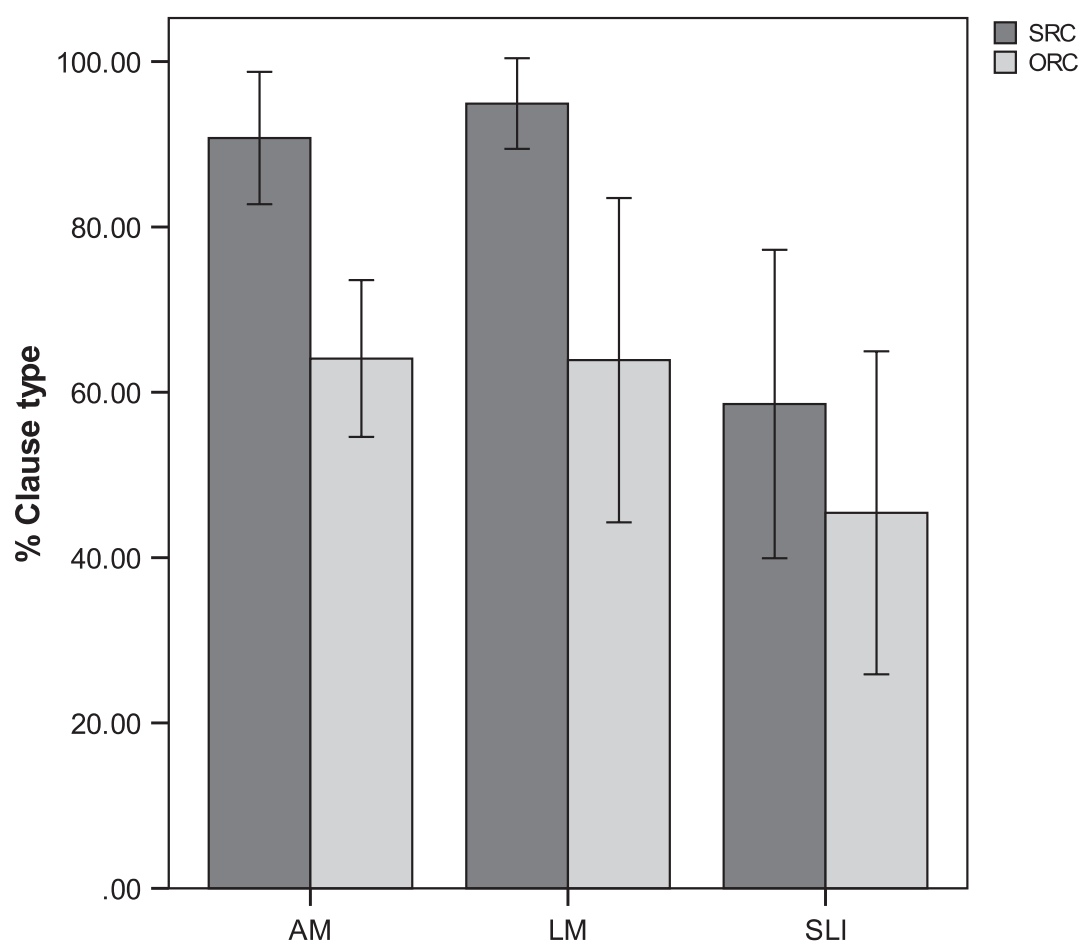

Fig. 2. Percentage of subject (SRC) and object relative (ORC) clauses produced regardless of context by the age-matched children (AM), the language-matched children (LM), and the children with SLI.

subject and object context regardless of whether it was the target $\mathrm{RC}$ type (Figure 2).

To examine whether the three groups differed in the number of RCs that they produced in the subject vs. the object context we conducted a two-way (RC context: subject, object) $\times$ three-way (Group: AM, LM, SLI) ANOVA. This revealed a main effect of $\mathrm{RC}$ context $(F(\mathrm{I}, 42)=34 \cdot \mathrm{I} 64$, $\left.p<0.00 \mathrm{I}, \eta^{2}=0.449\right)$, indicating that the number of $\mathrm{RCs}$ produced in the subject context differed from the number of RCs produced in the object context, and a main effect of Group $\left(F(\mathrm{I}, 4 \mathrm{I})=5.897, p=0.006, \eta^{2}=0 \cdot \mathrm{I} 60\right)$, indicating that the three groups differed from each other in the number of RCs that they produced. Post-hoc comparisons with Bonferroni correction showed that the AM and the LM children significantly differed from the children with SLI in the proportion of RCs that they produced in subject context $(\mathrm{SRC}: \mathrm{AM}=90 \cdot 8 \%, \mathrm{LM}=94 \cdot 9 \%, \mathrm{SLI}=58 \cdot 6 \%$; $\mathrm{AM}$ vs. SLI : $p=0.002$, LM vs. SLI $: p=0.004$ ). The AM and the LM children did not differ from the children with SLI in proportion of RCs produced in object 


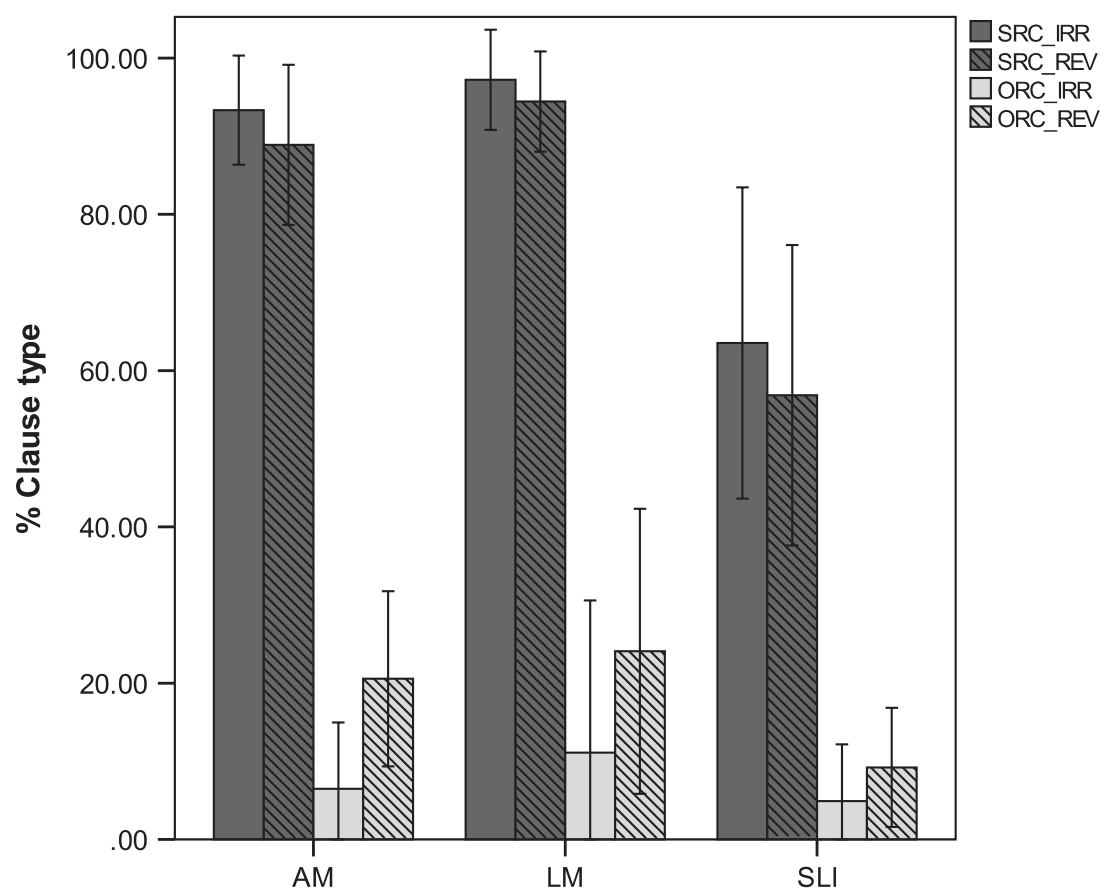

Fig. 3. Percentage of correct responses for subject (SRC) and object (ORC) reversible $(\mathrm{REV})$ and irreversible (IRR) relative clauses produced by the age-matched children (AM), the language-matched children (LM), and the children with SLI.

context $(\mathrm{ORC}: \mathrm{AM}=64 \cdot \mathrm{I} \%, \mathrm{LM}=63 \cdot 9 \%, \mathrm{SLI}=45 \cdot 4 \% ; p>0 \cdot \mathrm{I})$. Overall, then, the task was felicitous at eliciting relative clauses in both the subject and object context.

Subsequently, we calculated the target subject and object RCs produced depending on reversibility (Figure 3 ).

To examine whether there was an effect of $\mathrm{RC}$ type and reversibility we conducted a two-way (RC type: SRC, ORC) $\times$ two-way (Reversibility: reversible, irreversible) $\times$ three-way (Group: AM, LM, SLI) ANOVA. This revealed a main effect of $\mathrm{RC}$ type $(F(\mathrm{I}, 42)=238.799, p<0.00 \mathrm{I}$, $\left.\eta^{2}=0.853\right)$, suggesting that the SRCs differed from the ORCs, and a main effect of Group $\left(F(\mathrm{I}, 42)=9.945, p<0.00 \mathrm{I}, \eta^{2}=0.327\right)$, suggesting that the three groups differed from each other. There was no main effect of reversibility $\left(F(\mathrm{I}, 42)=\mathrm{I}_{5} \mathrm{I}_{3}, p>0.2, \eta^{2}=0.036\right)$, suggesting that there was no difference between the reversible and the irreversible sentences. A significant interaction between $\mathrm{RC}$ type and reversibility $(F(\mathrm{I}, 42)=\mathrm{I} 3.594$, $p=0.00 \mathrm{I}, \eta^{2}=0.480$ ) suggested that the proportion of reversible sentences differed from the irreversible sentences depending on $\mathrm{RC}$ type, as well as an 
interaction between $\mathrm{RC}$ type and Group $(F(\mathrm{I}, 42)=3.9 \mathrm{I} 8, p=0.028$, $\left.\eta^{2}=0 \cdot 160\right)$, suggesting that the three groups differed depending on the RC type. No other two- or three-way interactions were reported.

To unpack the interaction between $\mathrm{RC}$ type and reversibility we conducted three repeated-measures ANOVAs for the SRC and the ORC and for each group separately. For the SRCs there was no effect of reversibility for any of the groups. Post-hoc tests with Bonferroni correction showed that the children with SLI produced significantly fewer target reversible and irreversible SRCs than the AM children $(p=0.003)$, and the LM children $(p=0.02)$ (irreversible: $\mathrm{AM}=93.3 \%, \mathrm{LM}=97 \cdot 2 \%$, $\mathrm{SLI}=57 \cdot 9 \%$; reversible: $\mathrm{AM}=88.9 \cdot 5 \%, \mathrm{LM}=94 \cdot 4 \%, \mathrm{SLI}=56 \cdot 8 \%$ ).

For the ORC there was an effect of reversibility for the AM group only $\left(F(\mathrm{I}, \mathrm{I} 7)=6 \cdot \mathrm{I} 49, p=0.024, \eta^{2}=0.266\right)$, but not for the LM or the SLI group. Post-hoc tests with Bonferroni correction revealed that the three groups did not differ on the percentage of reversible and irreversible ORCs that they produced (irreversible: $\mathrm{AM}=6 \cdot 9 \%, \mathrm{LM}=\mathrm{II} \cdot \mathrm{I} \%, \mathrm{SLI}=4.9 \%$ reversible: $\mathrm{AM}=20 \cdot 6 \%, \mathrm{LM}=24 \cdot \mathrm{I} \%, \mathrm{SLI}=9 \cdot 2 \%)$.

A further analysis was carried out to investigate the strategies employed by all three groups of children when avoiding subject and object relative clauses. An analysis and comparison of the errors may reveal why all groups have problems producing SRCs and ORCs, but may also reveal the developmental changes underlying the acquisition of relative clauses and allow the identification of any deviant strategies used. For the SRCs, the avoidance strategies included simple, fragmented, as well as complementizer omission (Table I). For the ORCs, the avoidance strategies included role and theme reversals, passives (morphological, periphrastic), fragmented, and simple sentences.

To examine whether the three groups differed in the type of avoidance strategies that they used for SRCs we conducted a two-way (Reversibility: reversible, irreversible) $\times$ three-way (Avoidance strategy: simple, fragment, complementizer) $\times$ three-way (Group: AM, LM, SLI) ANOVA. This revealed a main effect of Avoidance strategy $(F(2,4)=\mathrm{I} 2.035, p<0.00 \mathrm{I}$, $\left.\eta^{2}=0.223\right)$, suggesting that the avoidance strategies differed from one another, and a main effect of $\operatorname{Group}\left(F(\mathrm{I}, 42)=\mathrm{I} 0.32 \mathrm{I}, p<0.00 \mathrm{I}, \eta^{2}=0.330\right)$, suggesting that the three groups differed from one another. A significant interaction between Avoidance strategy and Group $(F(\mathrm{I}, 42)=\mathrm{I} 3.5 \mathrm{I} 8$, $\left.p<0.00 \mathrm{I}, \eta^{2}=0.392\right)$, suggested that the three groups followed different avoidance strategies. There were no other main effects or interactions. Post-hoc comparisons using Bonferroni correction revealed that children with SLI produced significantly more simple sentences than the AM and the LM children for both the reversible and irreversible sentences ( $p<0.00$ I for all cases). The three groups did not differ on fragmented sentences or complementizer omissions. 
TABLE I. Percentage of avoidance strategies out of all responses, avoidance strategies and correct responses for subject relative clauses by the age-matched children $(A M)$, the language-matched children $(L M)$, and the children with SLI in the production task

Subject Relative Clauses

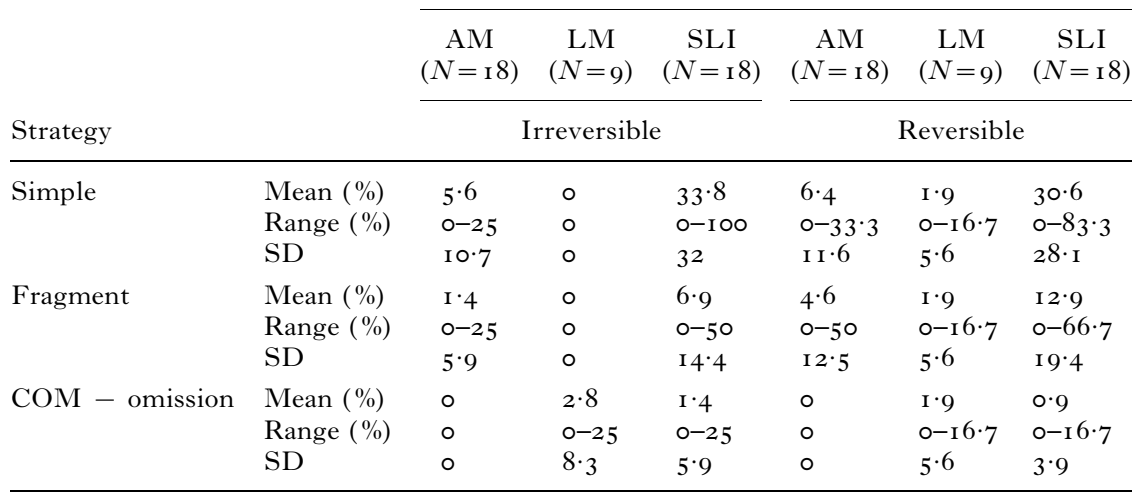

To unpack the interaction between Avoidance strategy and Group we ran three two-way (Reversibility: reversible, irreversible) $\times$ three-way (Avoidance strategy: simple, fragment, complementizer) repeated-measures ANOVAs for each group separately. This revealed a significant main effect of Avoidance strategy for the SLI group only $(F(2,34)=\mathrm{I} 7 \cdot 107, p<0 \cdot 00 \mathrm{I}$, $\left.\eta^{2}=0.502\right)$. Post-hoc comparisons using Bonferroni correction showed that the predominant error type was simple sentences, which significantly differed from fragmented sentences $(p<0.0 \mathrm{I})$ and complementizer omissions $(p<0.00 \mathrm{I})$, which also tended to differ from each other $(p=0.072)$.

To examine the avoidance strategies that the three groups used in the case of ORCs we calculated the proportion of head and role reversals, passives, simple, and fragmented sentences that the children produced (Table 2 ).

To examine whether the three groups differed in the type of errors that they produce in ORC we conducted a two-way (Reversibility: reversible, irreversible) $\times$ five-way (Avoidance Strategy: head reversal, role reversal, passives, simple, fragment) $\times$ three-way (Group: AM, LM, SLI) ANOVA. This revealed a main effect of Reversibility $(F(\mathrm{I}, 42)=5.439, p<0.05$, $\left.\eta^{2}=0.100\right)$, a main effect of Avoidance strategy $(F(\mathrm{I}, 42)=9.429, p<0.00 \mathrm{I}$, $\left.\eta^{2}=0.187\right)$, indicating that the various avoidance strategies differed from each other, and a significant interaction between Avoidance Strategy and Group $\left(F(\mathrm{I}, 42)=5.426, p<0.00 \mathrm{I}, \eta^{2}=0.209\right)$, suggesting that the three groups differed in the type of avoidance strategies they employed. Post-hoc comparisons with Bonferroni correction showed that the AM children produced fewer role-reversal errors than the children with SLI in the 
TABLE 2. Percentage of avoidance strategies out of all responses, avoidance strategies and correct responses for object relative clauses by the age-matched children $(A M)$, the language-matched children $(L M)$, and the children with SLI in the production task

\begin{tabular}{|c|c|c|c|c|c|c|c|}
\hline \multirow[b]{3}{*}{ Strategy } & & \multicolumn{6}{|c|}{ Object Relative Clauses } \\
\hline & & $\begin{array}{c}\mathrm{AM} \\
(N=\mathrm{I} 8)\end{array}$ & $\begin{array}{c}\mathrm{LM} \\
(N=9)\end{array}$ & $\begin{array}{c}\text { SLI } \\
(N=\text { I } 8)\end{array}$ & $\begin{array}{c}\text { AM } \\
(N=\text { I } 8)\end{array}$ & $\begin{array}{c}\text { LM } \\
(N=9)\end{array}$ & $\begin{array}{c}\mathrm{SLI} \\
(N=\mathrm{I} 8)\end{array}$ \\
\hline & & \multicolumn{3}{|c|}{ Irreversible } & \multicolumn{3}{|c|}{ Reversible } \\
\hline Role reversal & $\begin{array}{l}\text { Mean }(\%) \\
\text { Range }(\%) \\
\text { SD }\end{array}$ & $\begin{array}{l}6 \cdot 9 \\
\text { o-50 } \\
\text { I } 6 \cdot 7\end{array}$ & $\begin{array}{l}\text { I } 6 \cdot 7 \\
\text { o-75 } \\
27 \cdot 9\end{array}$ & $\begin{array}{l}29 \cdot 4 \\
\text { O-IOO } \\
28 \cdot 9\end{array}$ & $\begin{array}{l}5 \cdot 6 \\
0-33 \cdot 3 \\
9 \cdot 9\end{array}$ & $\begin{array}{l}\text { I I } 1 \\
0-50 \\
\text { I } 6 \cdot 7\end{array}$ & $\begin{array}{l}22 \cdot 2 \\
0-83 \cdot 3 \\
25 \cdot 9\end{array}$ \\
\hline Head reversal & $\begin{array}{l}\text { Mean }(\%) \\
\text { Range }(\%) \\
\text { SD }\end{array}$ & $\begin{array}{l}4 \cdot 2 \\
0-25 \\
9 \cdot 6\end{array}$ & $\begin{array}{l}5 \cdot 6 \\
0-25 \\
\text { I I }\end{array}$ & $\begin{array}{l}0 \\
0 \\
0\end{array}$ & $\begin{array}{l}3 \cdot 7 \\
0-50 \\
12 \cdot 2\end{array}$ & $\begin{array}{l}\mathrm{I} \cdot 9 \\
0-\mathrm{I} 6 \cdot 7 \\
5 \cdot 6\end{array}$ & $\begin{array}{l}0.9 \\
0-16 \cdot 7 \\
4\end{array}$ \\
\hline Passives & $\begin{array}{l}\text { Mean }(\%) \\
\text { Range }(\%) \\
\text { SD }\end{array}$ & $\begin{array}{l}55 \cdot 6 \\
\text { o- IOO } \\
35.9\end{array}$ & $\begin{array}{l}33 \cdot 3 \\
0-100 \\
37 \cdot 5\end{array}$ & $\begin{array}{l}\text { I } 4 \cdot 7 \\
\text { O-IOO } \\
26 \cdot 6\end{array}$ & $\begin{array}{l}50 \cdot 2 \\
0-50 \\
30 \cdot 9\end{array}$ & $\begin{array}{l}24 \cdot I \\
0-66 \cdot 7 \\
25 \cdot 2\end{array}$ & $\begin{array}{l}\text { I } 5 \cdot 9 \\
o-83 \cdot 3 \\
30 \cdot 1\end{array}$ \\
\hline Simple & $\begin{array}{l}\text { Mean }(\%) \\
\text { Range (\%) } \\
\text { SD }\end{array}$ & $\begin{array}{l}\text { I } 6 \cdot 7 \\
0-75 \\
24 \cdot 3\end{array}$ & $\begin{array}{l}22 \cdot 2 \\
0-75 \\
26 \cdot 4\end{array}$ & $\begin{array}{l}26 \cdot 9 \\
0-100 \\
3 I \cdot 3\end{array}$ & $\begin{array}{l}\mathrm{I} 4 \cdot 2 \\
O-50 \\
2 \mathrm{I} \cdot 9\end{array}$ & $\begin{array}{l}3 I \cdot 5 \\
0-66 \cdot 7 \\
24 \cdot 2\end{array}$ & $\begin{array}{l}30 \cdot 6 \\
0-83 \cdot 3 \\
3 I \cdot 6\end{array}$ \\
\hline Fragment & $\begin{array}{l}\text { Mean }(\%) \\
\text { Range }(\%) \\
\text { SD }\end{array}$ & $\begin{array}{l}\text { Io.2 } \\
\text { o- } 33.3 \\
9.9\end{array}$ & $\begin{array}{l}\text { I I } \cdot \text { I } \\
O-25 \\
\text { I } 3 \cdot 2\end{array}$ & $\begin{array}{l}24 \\
O-I O O \\
3 I \cdot 3\end{array}$ & $\begin{array}{l}4 \cdot 8 \\
0-33 \cdot 3 \\
9 \cdot 8\end{array}$ & $\begin{array}{l}7 \cdot 4 \\
0-16 \cdot 7 \\
8 \cdot 8\end{array}$ & $\begin{array}{l}21 \cdot 6 \\
0-100 \\
26 \cdot 3\end{array}$ \\
\hline
\end{tabular}

irreversible sentences $(p=0.028)$, more passives in the irreversible and reversible sentences $(p=0.002)$, more fragmented sentences in the reversible $(p=0.022)$ and irreversible sentences $(p=0.03 \mathrm{I})$, and more simple sentences in the reversible sentences $(p=0.025)$. Despite numerical differences, the LM children did not differ from the children with SLI or from the AM children on any of the avoidance strategies. This may be due to the small number of LM children.

Subsequently, we examined how consistently children opted for a particular avoidance strategy. A child was thought to consistently opt for a particular avoidance strategy if they chose this avoidance strategy $75 \%$ of the time ( 3 out of 4 for irreversible and 4 out of 6 for reversible sentences). In the case of the SRCs, there was no predominant avoidance strategy for the AM and the LM groups, because their error rates were very small in this condition. In the case of the children with SLI, four children $(22 \cdot 2 \%)$ opted for simple sentences in the case of irreversible sentences, and one child $(5 \cdot 5 \%)$ in the case of reversible sentences.

In the case of ORCs, seven AM children consistently opted for passive object relatives in the irreversible condition (38.9\% of the children) and 
TABLE 3. Complementizers (in \%) in subject relative clauses by the agematched children $(A M)$, the language-matched children $(L M)$, and the children with SLI in the production task

\begin{tabular}{|c|c|c|c|c|}
\hline \multirow[b]{2}{*}{ Complementizer } & & \multicolumn{3}{|c|}{ Subject Relative Clauses } \\
\hline & & $\operatorname{AM}(N=\mathrm{I} 8)$ & $\operatorname{LM}(N=9)$ & $\operatorname{SLI}(N=\mathrm{I} 8)$ \\
\hline Der & $\begin{array}{l}\text { Mean (\%) } \\
\text { Range (\%) } \\
\text { SD }\end{array}$ & $\begin{array}{l}85 \\
0-100 \\
33 \cdot 3\end{array}$ & $\begin{array}{l}84 \cdot 8 \\
\text { O-IO० } \\
30 \cdot 5\end{array}$ & $\begin{array}{l}95.9 \\
0-100 \\
9.6\end{array}$ \\
\hline Som & $\begin{array}{l}\text { Mean (\%) } \\
\text { Range (\%) } \\
\text { SD }\end{array}$ & $\begin{array}{l}\text { I } 3.9 \\
\text { O-IOO } \\
33.3\end{array}$ & $\begin{array}{l}7 \cdot 9 \\
0-40 \\
\text { I } 5 \cdot 7\end{array}$ & $\begin{array}{l}2 \cdot I \\
0-33 \cdot 3 \\
7 \cdot 8\end{array}$ \\
\hline Null complementizer & $\begin{array}{l}\text { Mean (\%) } \\
\text { Range (\%) } \\
\text { SD }\end{array}$ & $\begin{array}{l}\circ \\
\circ \\
\circ\end{array}$ & $\begin{array}{l}\circ \\
\circ \\
\circ\end{array}$ & $\begin{array}{l}2 \\
\mathrm{O}-9 \cdot \mathrm{I} \\
2 \cdot 3\end{array}$ \\
\hline Doubling & $\begin{array}{l}\text { Mean (\%) } \\
\text { Range (\%) } \\
\text { SD }\end{array}$ & $\begin{array}{l}I \cdot I \\
0 \\
0\end{array}$ & $\begin{array}{l}7 \cdot 3 \\
\text { o-46.2 } \\
\text { I } 6\end{array}$ & $\begin{array}{l}\circ \\
\circ \\
\circ\end{array}$ \\
\hline
\end{tabular}

eight in the reversible condition ( $44 \cdot 4 \%$ of the children). In the LM group, there was no predominant consistent pattern, as only one child consistently opted for passive object relatives and simple sentences. The children with SLI exhibited a distributed profile, opting for simple sentences (four children in the reversible and one in the irreversible condition), passive object relatives (three children in the reversible and one in the irreversible condition), fragments ( 3 children) and role reversals ( I child in the reversible condition).

A final analysis was carried out to examine whether the three groups differed in the type of complementizer that they produced in subject and in object position. Note that the complementizers der or som are can be used interchangeably in SRCs and their presence is obligatory, hence their omission would constitute an ungrammatical option. In the case of ORCs, the complementizer som is optional, therefore its omission would constitute a grammatical option. Table 3 illustrates the results for the complementizers produced in SRC contexts.

To examine whether children with SLI differed from the AM and LM children in terms of complementizers used in SRCs we ran a four-way (Complementizer: der, som, double, null) $\times$ three-way (Group: AM, LM, SLI) ANOVA. This revealed a main effect of Complementizer $(F(3, \mathrm{I} 26)=$ $\left.70.603, p<0.001, \eta^{2}=0.627\right)$, suggesting that the types of complementizers differed. No other main effects or interactions were reported. Pairwise comparisons with Bonferroni correction showed that for all groups the complementizer der was the main complementizer used. 
TABLE 4. Complementizers (in \%) in object relative clauses by the age-matched children $(A M)$, the language-matched children $(L M)$, and the children with SLI in the production task

\begin{tabular}{|c|c|c|c|c|}
\hline \multirow[b]{2}{*}{ Complementizer } & & \multicolumn{3}{|c|}{ Object Relative Clauses } \\
\hline & & $\mathrm{AM}(N=\mathrm{IO})$ & $\operatorname{LM}(N=6)$ & $\operatorname{SLI}(N=8)$ \\
\hline Som & $\begin{array}{l}\text { Mean (\%) } \\
\text { Range (\%) } \\
\text { SD }\end{array}$ & $\begin{array}{l}46 \cdot 5 \\
0-100 \\
59 \cdot 5\end{array}$ & $\begin{array}{l}35 \cdot 8 \\
0-100 \\
43 \cdot 6\end{array}$ & $\begin{array}{l}66 \cdot 7 \\
0-100 \\
47 \cdot I\end{array}$ \\
\hline Null complementizer & $\begin{array}{l}\text { Mean (\%) } \\
\text { Range (\%) } \\
\text { SD }\end{array}$ & $\begin{array}{l}53 \cdot 5 \\
0-100 \\
50.6\end{array}$ & $\begin{array}{l}64 \cdot 2 \\
0-100 \\
43 \cdot 6\end{array}$ & $\begin{array}{l}33 \cdot 3 \\
0-100 \\
47 \cdot 1\end{array}$ \\
\hline
\end{tabular}

Subsequently, we examined complementizer omission in the ORC context (Table 4). Note that complementizer production in this context is optional.

To examine whether children with SLI differed from the AM and LM children in terms of the complementizers that they produced in ORCs, we ran a two-way (Complementizer: som, null) $\times$ three-way (Group: AM, LM, SLI) ANOVA. This revealed no main effects or interactions, suggesting that the children with SLI did not differ from their AM or LM TD controls in the use of complementizers in ORCs.

Comprehension vs. production. Finally, we conducted a two-way (Modality: production, comprehension) $\times$ two-way $(\mathrm{RC}$ type: SRC, ORC) $\times$ three-way (Group: AM, LM, SLI) ANOVA to examine the relationship between the production and comprehension of SRCs and ORCs in the three groups. This revealed a main effect of Modality $\left(F(\mathrm{I}, 4 \mathrm{I})=\mathrm{I} 87 \cdot 225, p<0.00 \mathrm{I}, \eta^{2}=0.820\right)$, suggesting that the two modalities differed from each other, a main effect of RC type $(F(\mathrm{I}, 4 \mathrm{I})=307 \cdot 7 \mathrm{I} 6$, $\left.p<0.00 \mathrm{I}, \eta^{2}=0.882\right)$, indicating that performance differed depending on $\mathrm{RC}$ type, a main effect of $\operatorname{Group}\left(F(\mathrm{I}, 4 \mathrm{I})=27.7 \mathrm{I} 3, p<0.00 \mathrm{I}, \eta^{2}=0.526\right)$, suggesting that the groups differed from each other, a significant interaction between Modality and RC type $\left(F(\right.$ I, 4I $)=$ I 29.799, $\left.p<0.00 \mathrm{I}, \eta^{2}=0.760\right)$, and a significant three-way interaction between Modality, RC type, and Group $\left(F(\mathrm{I}, 4 \mathrm{I})=\mathrm{I} 5.476, p<0.00 \mathrm{I}, \eta^{2}=0.430\right)$.

To unpack the three-way interaction between Modality, RC type, and Group we ran a two-way (Modality: production, comprehension) ANOVA for each RC type and Group separately. For the SRCs, this revealed no main effect of Modality for the AM and the LM groups; a main effect of Modality was found for the SLI group $(F(\mathrm{I}, 4 \mathrm{I})=\mathrm{I} 2.087, p=0.003$, $\eta^{2}=0.4 \mathrm{I} 6$ ), suggesting that for the SLI children there was a discrepancy in their performance on the production vs. the comprehension task, as they 
performed better on the comprehension $(79.4 \%)$ of SRCs than on their production $(56 \cdot 3 \%)$.

For the ORCs a repeated-measures ANOVA revealed a main effect of Modality for all groups (AM: $\left(F(\mathrm{I}, \mathrm{I} 7)=329.9 \mathrm{I} 9, p<0.00 \mathrm{I}, \eta^{2}=0.959\right.$; $\mathrm{LM}: \quad\left(F(\mathrm{I}, 8)=\mathrm{I} 72.022, \quad p<0.00 \mathrm{I}, \quad \eta^{2}=0.956 ; \quad \mathrm{SLI}: \quad(F(\mathrm{I}, \mathrm{I} 7)=95.982\right.$, $\left.\left.p<0.00 \mathrm{I}, \eta^{2}=0.857\right)\right)$. All three groups had better performance on the comprehension of ORCs compared to production.

\section{DISCUSSION}

This is the first study to examine the comprehension and production of relative clauses in Danish children with SLI, and to compare them with their $\mathrm{AM}$ and LM peers. It further addressed particular avoidance strategies that Danish children opt for when they do not produce the target relative clause.

The first research question that we addressed was whether Danish children with SLI differ from their AM and LM peers in the comprehension of RCs, as previously reported (Friedmann \& Novogrodsky, 2004). Results showed that all three groups had more difficulties with non-canonical RCs, namely ORCs, than with canonical SRCs. Furthermore, children with SLI did not differ from the two groups of TD children in terms of SRCs, but performed at chance level in the comprehension of ORCs, suggesting that this RC type is particularly problematic for children with SLI. This pattern is consistent with previous studies on the comprehension of subject and object relatives that have used the same tasks in typologically different languages (Contemori \& Garraffa, 2010; Friedmann \& Novogrodsky, 2004; Novogrodsky \& Friedmann, 2006).

The problematic nature of ORCs for all groups of children and especially for the children with SLI was revealed in the production task. Namely, children overall produced more SRCs than ORCs and the difference was significant for all three groups. Additionally, the children with SLI produced significantly fewer SRCs than the AM and LM group, whereas the three groups did not differ statistically in the amount of ORCs that they produced, although there was a numerical difference.

The question that arises at this point is which theories could help us account for the performance of the children with SLI on the comprehension and the production tasks. Two factors will help us address this question. The first is the comparison of their performance on the tasks tapping into different modalities and the two types of relative clauses, that is, SRCs vs. ORCs. Second, we will explore what different avoidance strategies can tell us about the grammatical source of the impairment.

Accounts that capitalize on linear order (e.g. Cromer, I978) predict that children with SLI would perform better on SRCs than on ORCs in the comprehension task. More specifically, performance on ORCs was 
predicted to be well below chance. Although the children with SLI did perform better on SRCs compared to ORCs, their performance on ORCs was at chance level and not below chance, similarly to what Friedmann and Novogrodsky (2004) have reported for Hebrew-speaking children. Therefore, our findings cannot support this account.

Turning to theories that argue for representational deficits in the domain of movement and thematic role assignment (Friedmann \& Novogrodsky, 2004; Novogrodsky \& Friedmann, 2006; van der Lely \& Battell, 2003), the performance pattern that the children with SLI exhibited in the comprehension task seems to corroborate their claims. According to the RDDR theory (van der Lely, I996), the assignment of thematic roles to noun phrases that have undergone long-distance movement will be optional, and this will lead to chance performance in comprehension. The inability to assign a thematic role to a displaced constituent from an object position is also argued by Friedmann and Novogrodsky (2004). In this account, the mismatch between the position of the displaced constituent as the head of the relative clause and its thematic role, i.e. the patient or the theme of the relative clause, will lead to a guessing strategy in comprehension. The predictions of these two theories are borne out in the comprehension of ORCs, in which children with SLI performed at chance level on the comprehension of ORCs, and significantly more poorly compared with their TD AM and LM peers.

Regarding production, the RDDR would again predict chance performance in terms of accuracy on ORCs. The findings in our study did not corroborate this prediction, as the children with SLI had very low accuracy on ORCs. Given the low occurrence of ORCs in the production task, the avoidance strategies that the children used may be more informative regarding their underlying problems with relative clauses. In the SRC context, the children with SLI opted for more simple sentences when an SRC was avoided. In the ORC context, the children with SLI produced significantly more role or theme reversals but fewer passive object relatives compared with the AM children. The thematic role errors observed in the ORCs have been accounted for by Novogrodsky and Friedmann (2006) as being related to deficits in movement and thematic role assignment in children with SLI. However, Danish children with SLI produced passive object relatives as avoidance strategies as well, yet to a lower degree compared with their AM peers. Production of passive object relatives by children with SLI has not been found in other studies and is contrary to the findings reported by Novogrodsky and Friedmann (2006), where passive ORCs were never produced by Hebrew-speaking children. Although this may reflect input frequencies in the target language, i.e. passives are infrequent in Hebrew (Friedmann \& Novogrodsky, 2004), whereas they are frequent in Danish (Faarlund, Svein \& Vannebo, I997), it may also reflect cross-linguistic 
differences between Hebrew and Danish, as well as underlying grammatical competencies.

Cross-linguistic differences in the acquisition of passives have been reported by Armon-Lotem et al. (unpublished observations) who compared comprehension of passives by five-year-old children in eleven different languages. In this study, Danish five-year-old children were at ceiling in terms of the comprehension of passives, whereas Hebrew-speaking children performed at chance level, suggesting that passives are acquired early in Danish. The fact that the typically developing AM and LM children in our study also produced many passive object relatives as avoidance strategies further supports the claim that passives are acquired early in Danish and can be used productively in various contexts, even within a relative clause. The findings from the present study are also in line with the study of TD Danish children by Jensen de López and Sundahl Olsen (2010), who found that passive object relatives are the predominant avoidance strategy.

One of the novel findings in our study was that the children with SLI were able to produce passive object relative clauses instead of active ORCs, although to a lesser extent than their TD peers. This finding suggests that their knowledge of theta-role assignment is not completely impaired and that they are able to employ this knowledge when constrained to produce active ORCs. This would further suggest that children with SLI differentiate between the two types of movement and that A-movement associated with passives may be easier than long-distance movement, such as $\mathrm{A}^{\prime}$-movement, associated with relative clauses. The argument that different types of movement may have different degrees of difficulty in acquisition has been put forward by Jakubowicz and Tuller (2008). In their study with French children with SLI, they propose that children with SLI have problems with wh-questions depending on the degree of embedding.

The production of SRCs and passive object relatives, that is SRCs containing a passive structure, indicates that both TD children and children with SLI differentiate between the two RC types and find the production of SRCs easier than the production of ORCs. However, the previously mentioned theories fail to account for why TD children and children with SLI differentiate between the two types of RCs and why they opt for passive object relatives (Novogrodsky \& Friedmann, 2006).

Two recent studies by Belletti (2009) and Friedmann et al. (2009) attempt to combine the better performance on SRCs compared to ORCs with the preference for passive object relatives by examining two factors: (a) the nature of movement from the subject, as in the case of SRCs vs. the object position, as in the case of ORCs; and (b) the type of noun phrase that intervenes between the head of the $\mathrm{RC}$ and the object within the $\mathrm{RC}$. Belletti's (2009) account capitalizes on Collins' (2005) 'smuggling' approach to copular passives in English and on the Relativized Minimality (RM) 
account proposed by Rizzi (I990) and applied to the comprehension of object relatives by Friedmann et al. (2009).

According to the RM (Rizzi, I990), in a configuration such as the following $\mathrm{X}$...Z...Y, the relation between $\mathrm{X}$ and $\mathrm{Y}$ cannot hold if $\mathrm{Z}$ is a potential candidate for the local relation. In terms of $\mathrm{RCs}$ this would mean that the position of $\mathrm{X}$ is the target (head), $\mathrm{Z}$ the intervener (subject), and $\mathrm{Y}$ the origin (object), as in (I8). In an ORC the noun needs to move from the $\mathrm{Y}$ position to the $\mathrm{X}$ position with the subject intervening. Friedmann et al. (2009) argue that the problem children face with comprehending ORCs is related to the presence of the intervening subject, which is placed between the head of the RC and the position from where the head of the RC, i.e. the object, moved.

$$
[\mathrm{CP} \cdots \overbrace{}^{[\mathrm{TP}} \mathrm{DP}[\mathrm{vP} \ldots \mathrm{V} \text { DP }]]
$$

What Belletti (2009) proposes is that in order for children to overcome this problem they adopt what is called by Collins a 'smuggling approach. In this approach, the verb in the passive construction and the internally merged direct object are moved first, and beyond the position of the subject, becoming the head of the $\mathrm{RC}$ and thus avoiding the locality or RM violation that the presence of the external argument (subject) would evoke, as in (I9).

$$
\left[\mathrm { CP } \ldots \left[\begin{array}{c}
\mathrm{TP} \\
\uparrow
\end{array}\right.\right.
$$

Similarly in production, children prefer to use a passive object relative instead of an ORC, because they find 'smuggling' the verb and its internal argument past the external argument and to the head of the $\mathrm{RC}$ easier than producing a structure with an intervening subject, where the internal argument has moved non-locally to the head of the RC. As Belletti (2009) notes, although the derivation in (r9) looks more costly, it is not, as each step movement is shorter than in ( 18 ), and intervention is avoided.

If this account then holds for Danish, it would mean that the production of SRCs and passive object relatives may be easier than active ORCs, when language-specific factors allow it. At the same time, it would explain why Danish TD children adopt this strategy to a great extent and would suggest that children with SLI may optionally prefer to perform step-by-step 'smuggling' instead of long-distance movement, since this is less costly for them. This operation may be less demanding in terms of processing, and viewed similarly to the cognitive process of 'chunking', which consists of organizing larger elements into shorter elements, which are easier to hold in memory (Miller, I956). We would like to suggest that this is the case for the Danish TD children, but to a lesser degree for the impaired children. Given, though, that Danish children with SLI differ from their TD AM 
but not from their LM peers in terms of SRCs, passive object relatives, and thematic role-reversal errors that they produced suggests that children with SLI are in a previous developmental stage and that their grammatical knowledge is delayed. The findings from the present study can be further explored in the future by comparing different types of movement (A-movement and $\mathrm{A}^{\prime}$-movement) in the same group of SLI children. It would be interesting to explore whether or not the same Danish children with SLI experience problems with passives to the same degree as for relative clauses. The subject-object asymmetry in relative clauses would also suggest that both Danish TD children and children with SLI are sensitive to intervention effects. In the future it would be interesting to investigate whether the factors that influence ORC production and comprehension are the same for the TD and the SLI children, using different intervention contexts (see Friedmann et al., 2009). These comparisons would feed into the theories of SLI entertained in the present article, in order to better ascertain the areas of grammatical deficit in the language-impaired children.

Finally, the claim that children with SLI have problems reorganizing the structure of subordinate clauses cannot be supported by our data, since the children with SLI did not differ from the TD children in the type and amount of complementizers they produced. All groups opted for the complementizer der in SRCs; the three groups did not differ in terms of complementizers in object position, where they are optional.

When these results are viewed in conjunction with the results from the younger Swedish-speaking children reported in earlier studies, it seems that the Swedish SLI children (Håkansson \& Hansen, 2000) and the Danish SLI children are at different points on the developmental path, with the older Scandinavian-speakers gradually becoming aware of the lexical complementizer insertion rule. It is very possible that the children in the Håkansson and Hansen (2000) study still have problems with the structural make-up of an embedded clause, such as a relative clause, whereas the children in our study are in the process of overcoming this stage. Additionally, the Hakansson and Hansson study used an act-out and an imitation task, which may be more challenging for young children than the elicitation task used in the present study. These cross-linguistic differences may be worth exploring in the future with children with SLI of different ages and by using a variety of tasks that tap into different modalities.

\section{REFERENCES}

Adani, F. (20II). Rethinking the acquisition of relative clauses in Italian: Towards a grammatically based account. Fournal of Child Language 38, I4I-65.

Belletti, A. (2009). Notes on passive object relatives. In P. Svenonius (ed.), Functional structure from top to toe. Oxford: Oxford University Press. 
Belletti, A. \& Contemori, C. (2010). Intervention and attraction. On the production of subject and object relatives by Italian (young) children and adults. In J. Costa, A. Castro, M. Lobo \& F. Pratas (eds), Proceedings of Gala 2009. Language acquisition and development, 39-52. Cambridge: Cambridge Scholars.

Bishop, D. V. M. (2010). Test for Reception of Grammar-Version 2. TROG-2 Vejledning. Copenhagen: Pearson Assessment.

Chomsky, N. (r993). A Minimalist Program for linguistic theory. In K. L. Hale \& S. J. Keyser (eds), The view from building 2O, I-52. Cambridge, MA: MIT Press.

Collins, C. (2005). A smuggling approach to the passive in English. Syntax 8, 8I-I 20.

Contemori, C. \& Garraffa, M. (2010). Comparison of modalities in SLI syntax: A study on the comprehension and production of non-canonical sentences. Lingua r20, I940-55.

Crain, S., McKee, C. \& Emiliani, M. (I990). Visiting relatives in Italy. In L. Frazer \& J. de Villiers (eds), Language processing and language acquisition, 335-56. Dordrecht: Kluwer.

Cromer, R. F. ( 1978). Hierarchical disability in the syntax of aphasic children. International Fournal of Behavioral Development $\mathbf{I}, 39 \mathrm{I}-402$.

de Villiers, J. G., Tager-Flusberg, H. B., Hakuta, K. \& Cohen, M. (I979). Children's comprehension of relative clauses. Fournal of Psycholinguistic Research 8, 499-5 I8.

Diessel, H. \& Tomasello, M. (2000). The development of relative clauses in spontaneous child speech. Cognitive Linguistics II , I 3 I-5 I.

Eisenberg, S. (2002). Interpretation of relative clauses by young children: Another look. Fournal of Child Language 29, I77-88.

Faarlund, J., Svein, L. \& Vannebo, K. (I997). Norsk Referanse-Grammatikk. Oslo: Universitetsforlaged Oslo.

Friedmann, N., Belletti, A. \& Rizzi, L. (2009). Relativized relatives: Types of intervention in the acquisition of A-bar dependencies. Lingua I I9, 67-88.

Friedmann, N. \& Novogrodsky, R. (2004). The acquisition of relative clause comprehension in Hebrew: A study of SLI and normal development. Fournal of Child Language 3r, 66I-8I .

Grillo, N. (2008). Generalized minimality: Syntactic underspecification in Broca's aphasia (LOT Dissertation Series I 86). Utrecht: Utrecht Publishing \& Archiving Services.

Grodzinsky, Y. (I990). Theoretical perspectives on language deficits. Cambridge, MA: MIT Press.

Guasti, M. T. (2002). Language acquisition: The growth of grammar. Cambridge, MA: MIT Press.

Håkansson, G. \& Hansson, K. (2000). Comprehension and production of relative clauses: A comparison between Swedish impaired and unimpaired children. Fournal of Child Language 27, 3 I 3-33.

Hamburger, H. \& Crain, S. (1982). Relative acquisition. In S. Kuczaj II (ed.), Language development, vol. I: Syntax and semantics, 245-74. Hillsdale, NJ : Erlbaum.

Hendricks, P. \& Koster, C. (2010). Production/comprehension asymmetries in language acquisition. Lingua 120, I 887-97.

Jakubowicz, C. \& Tuller, L. (2008). Specific language impairment in French. In D. Ayoun (ed.), Studies in French applied linguistics, 97-I 34. Amsterdam: John Benjamins.

Jensen de López, K. \& Sundahl Olsen, L. (2010). A view on the development of relative clauses in Danish. In H. Vejleskov (ed.), Børnesprog: Fra I2. Nordiske Symposium om Børnesprogsforskning [Child Language: Proceedings from the I 2 th Nordic Symposium on Research on Child Language], 40-46. Copenhagen: Professionshøjskolen UCC.

Kidd, E. \& Bavin, E. L. (2002). English-speaking children's understanding of relative clauses: Evidence for universal-cogntive and language-specific constraints on development. Fournal of Psycholinguistic Research 31, 599-6 I9.

Kidd, E., Brandt, S., Lieven, E. \& Tomasello, M. (2007). Object relatives made easy: A cross-linguistic comparison of the constraints influencing young children's processing of relative clauses. Language and Cognitive Processes 22, 860-97.

Leonard, L. B. (I998). Children with specific language impairment. Cambridge, MA: MIT Press. 
Lundin, B. (1987). Bisatser $i$ små barns språk. Lund: Lund University Press.

Marinis, T. \& van der Lely, H. K. J. (2007). On-line processing of wh-questions in children with G-SLI and typically developing children. International Fournal of Language $\mathcal{E}^{\circ}$ Communication Disorders 42, 557-82.

Marshall, C. R., Marinis, T. \& van der Lely, H. K. J. (2007). Passive verb morphology: The effect of phonotactics on passive comprehension in typically developing and Grammatical-SLI children. Lingua II 7, I 434-47.

Mckee, C. \& McDaniel, D. (200I). Resumptive pronouns in English relative clauses. Language Acquisition 9, I I 3-56.

Meisel, J. \& Müller, N. (I992). Finiteness and verb placement in early child grammar: Evidence from simultaneous acquisition of French and German in bilinguals. In J. Meisel (ed.), The acquisition of verb placement, 109-1 38 . Dordrecht: Kluwer.

Miller, G. A. (1956). The magical number seven, plus or minus two: Some limits on our capacity for processing information. Psychological Review 63, 8I-97.

Newmeyer, F. J. (1 997). Genetic dysphasia and linguistic theory. Fournal of Neurolinguistics Io, $47-73$.

Novogrodsky, R. \& Friedmann, N. (2006). The production of relative clauses in syntactic SLI : A window to the nature of the impairment. Advances in Speech-Language Pathology $8,364-75$.

Rizzi, L. (I990). Relativized minimality. Cambridge, MA: MIT Press.

Schuele, C. M. \& Dykes, J. C. (2005). Complex syntax acquisition: A longitudinal case study of a child with specific language impairment. Clinical Linguistics and Phonetics 19, 295-3 I 8 .

Schuele, C. M. \& Nichols, L. M. (2000). Relative clauses: Evidence of continued linguistic vulnerability in children with specific language impairment. Clinical Linguistics $\Xi^{\circ}$ Phonetics 14, 563-85.

Schuele, C. M. \& Tolberrt, L. (200I). Omissions of obligatory relative markers in children with specific language impairment. Clinical Linguistics \& Phonetics I5, 257-74.

Stavrakaki, S. (200I). Comprehension of reversible relative clauses in Specifically Language Impaired and Normally Developing Greek children. Brain $\sigma^{\circ}$ Language 77, 4I9-3I.

Stavrakaki, S. (2002). A-bar movement constructions in Greek children with SLI: Evidence for deficits in the syntactic component of language. In E. Fava (ed.), Clinical linguistics: Theory and applications in speech pathology and therapy (Current Issues in Linguistic Theory 227), I 3 I-55. Amsterdam: John Benjamins.

Taraldsen, K. T. (I99I). Two arguments for functional heads. Lingua 84, 85-ro8.

van der Lely, H. K. J. (I996). Specifically language impaired and normally developing children: Verbal passive vs. adjectival passive sentence interpretation. Lingua 98, 243-72.

van der Lely, H. K. J. \& Battell, J. (2003). Wh-movement in children with grammatical SLI : A test of the RDDR hypothesis. Language 79, I 53-8I.

Vikner, S. (I 99I). Relative der and other Co elements in Danish. Lingua 84, го9-136.

Wechsler, D. (I 99I). WISC-III. Copenhagen: Pearson Assessment.

Wechsler, D. (2004). WPPSI-R. Copenhagen: Pearson Assessment. 